\title{
TRES CABEZAS COLOSALES OLMECAS PROCEDENTES DE SAN LORENZO TENOCHTITLAN, EN EL NUEVO MUSEO DE ANTROPOLOGIA DE XALAPA*
}

BeAtriz de la Fuente

Cuando hace algunos años escribí acerca de la escultura olmeca, y en particular sobre las Cabezas Colosales, ${ }^{1}$ incluí en mis escritos a dos de las tres Cabezas que, desde septiembre de 1986, se guardan en el Nuevo Museo de Antropología de la Universidad Veracruzana en Xalapa, Veracruz.

Me referí entonces a la Cabeza número 7 , descubierta por Gallegos en $1969,{ }^{2}$ a la cual se le dio el nombre de Monumento 53, y también hice mención de la Cabeza número 8, descubierta en 1970 y reportada en el mismo año por Brügemann y Hers; a ésta se la llamó Monumento 61. Ambas permanecieron enterradas en San Lorenzo desde su hallazgo hasta el traslado al nuevo museo.

Durante los años de mis escritos, aún no se había reportado la tercera Cabeza que hoy está en dicho museo; fue descubierta por un campesino el 8 de agosto de 1982, posteriormente fue publicada en la revista México desconocido y de ella rindió informe el arqueólogo Román Piña Chán. ${ }^{3}$ Le corresponde el número 9, siguiendo el orden de las Cabezas, y el de Monumento 67, de acuerdo con la numeración general de las esculturas encontradas en San Lorenzo. Los números son progresivos según las fechas del hallazgo.

Este artículo tiene por objeto incorporar las tres "nuevas" Cabezas al conjunto antes estudiado, a fin de dar a conocer medidas correctas, piedra en que se labraron y analizarlas con base en sus formas y su patrón armó-

* Agradezco al maestro Fernando Winfield Capitaine, director del Museo de Antropo. logía de la Universidad Veractuzana en Xalapa, el obsequio de las fotos que ilustran este artículo y las medidas correctas de las cabezas, y a mi colega el arquitecto Manuel González Galván la realización de los dibujos sobre los que tracé la sección áurea.

1 Fuente, Beatriz de la "En toino a las nuevas cabezas olmecas", Anales del Instituto de Investigaciones Estéticas, No 40, pp. 5-11, Universidad Nacional Autónoma de México, México, 1971 Escultura monumental olmeca Catálogo, Instituto de Investigaciones Estéticas, Universidad Nacional Autónoma de México, México, 1973. Las cabezas colosales olmecias, Fondo de Cultura Económica, México, 1975

2. En el Catálogo sobre Escultura morumental olmeca, 1973:231, se dice erróneamente que fue descubierta por $F$. Beverido.

${ }^{3}$ Información verbal proporcionada por el Maestro Fernando Winfield Capitaine, Director del Museo de Antropología de Xalapa. 
nico. Ahora que es posible apreciarlas cabalmente, pueden integrarse al conjunto de Cabezas Colosales que a la fecha conocemos. Suman 16 en total. Nueve proceden de San Lorenzo, Veracruz; cuatro de La Venta, Tabasco; dos de Tres Zapotes, Veracruz (se les conoce como Monumento A - Monumento 1 de Tres Zapotes y Monumento Q o Monumento 2 de Tres Zapotes, se la nombra también Nestepe 1), y una del Rancho de Cobata en el Cerro El Vigía, Veracruz. No incluyo en el conjunto a otros monolitos, uno de los cuales se ha dicho que era un bloque que se iba a tallar como Cabeza, es el caso del llamado "Monumento del Ojochi", y de otro se supone que fue Cabeza, pero que debido al desgaste y la erosión no conserva sus formas; es el Monumento 50. 'Ambos están irreconocibles.

Queda establecido que son 16 las Cabezas Colosales y que, exceptuando la de Cobata, son esculturas olmecas. Insisto en el número de las Cabezas debido a que en publicación reciente, Miller ${ }^{4}$ dice que en San Lorenzo se encontraron diez. Tal vez tomó en consideración los monumentos amorfos arriba mencionados, y carecía de información acerca de la 9. De aquí en adelante llamaré a las Cabezas por el sitio en que se hallaron y según el número que les ha sido dado, por ejemplo San Lorenzo 9, o La Venta 1.

Las Cabezas comparten valores de forma y tienen también semejante significado: representan, fundamentalmente, rostros de gobernantes; son sus retratos. Individuos jóvenes, que revelan en su fisonomía atlética el control sobre sí mismos. No hay dos cabezas iguales, cada una exhibe poderosa individualidad en sus rasgos y en su expresión facial. Se ornamentan con distintos tocados y diversas orejeras: ahí otro aspecto de su carácter singular. Quien mira con detenimiento las dieciséis cabezas, no podrá confundir la vigorosa energía de Nestepe 1 con la complacencia de San Lorenzo 3; el ensimismamiento de San Lorenzo 4 con la sonriente placidez de San Lorenzo 9. También reconocerá, de inmediato, la talla irreprochable de todas las de San Lorenzo, entre las cuales sobresalen la 1, la 4, la 5 y la 8, así como el descuido en el labrado de las de La Venta, y en la 1 de Tres Zapotes. En la Cabeza de Cobata no se reconoce la vitalidad que anima el rostro de las demás; rasgos faciales y tocado fueron apenas relevados, los ojos se miran cerrados, y la boca, de labio superior extendido como tensa banda horizontal, termina en rígidas comisuras vueltas hacia abajo.

Además de la forma y el significado explícito, las Cabezas simbolizan conceptos más profundos y universales. En las Cabezas reside lo que se

${ }^{4}$ Miller, Mary Ellen. The art of Mesoamerica. From Olmec to Aztec, p. 21, Thames and Hudson, 1986. 
considera inmutable y eterno: la capacidad de comulgar con to sobrenatural. Representan, además, el asiento de la naturaleza divina del hombre; por ello no fueron aniquiladas, y tan sólo se dañó, en ocasiones, su apariencia visible y externa. A las Cabezas de piedra, lo mismo que a sus modelos mundanos, se les atribuían poderes divinos, por ello eran considerados objetos sagrados. Quiero hacer hincapié en otra cualidad de las Cabezas Colosales que debe ser nuevamente considerada. Se trata de la armonía de proporciones que se muestra en casi todas; de la relación de orden entre sus partes constitutivas por la presencia de un patrón matemático. Me refiero al sistema de proporción usado en las esculturas olmecas, que explica la impresión de su justo equilibrio, de la armonía de sus partes y de la belleza exacta de sus ritmos. Es lo que se ha llamado indistintamente "divina proporción", "sección áurea", "número de oro" o "sección $\emptyset "$. La presencia del sistema de proporción aplicado a las esculturas olmecas no implica el conocimiento del principio pitagórico, sino la coincidencia de la sabiduría humana acerca de las leyes que ordenan la naturaleza.

Ahora bien, la "sección áurea" aplicada a las Cabezas Colosales revela diferencias explicables por los cambios que las formas sufren con el tiempo, y por las voluntades de forma expresadas en los estilos locales. De este modo, la "sección áurea" de San Lorenzo 4 es distinta de la de La Venta 2; aquélla es más perfecta en su proporción armónica, ésta es definitivamente menos rigurosa; también es distinta San Lorenzo 1, de Tres Zapotes 1, en la primera se aprecia cierta variación respecto al orden perfecto; en la segunda la proporción casi ha desaparecido. Podemos suponer que las Cabezas que no muestran tal principio de orden, fueron realizadas en las postrimerías de la cultura olmeca, cuando el principio rector perdía significado. Las Cabezas con definida y manifiesta armonía fueron talladas cuando la estructura que los gobierna era dispuesta por sus creadores y comprendida y aceptada por la comunidad.

\section{Consideraciones históricas acerca del término olmeca y su relación con las Cabezas Colosales}

Fue hace más de un siglo, cuando en 1853 los campesinos avecindados en la hacienda de Hueyapan, hoy Tres Zapotes, Veracruz, encontraron la Cabeza Colosal; años más tarde, en 1862, José Melgar, supo de ella, la fue a observar y la publicó en 1869 y en 1871, haciendo personales comentarios ante tan espectacular hallazgo. 
Así, dice que resultó sorprendido ya que "como obra de arte es sin exageración una magnífica escultura... pero lo más me impresionó fue el tipo etiópico que representa; reflexioné que indudablemente había habido negros en este país, y esto había sido en los primeros tiempos del mundo: aquella Cabeza no sólo era importante para la arqueología mexicana, sino también para la del mundo en general, pues ponía en evidencia un hecho cuyas consecuencias lo eran".

Desde el siglo XVIII se especulaba acerca del origen de los antiguos mexicanos, y el hallazgo de la Cabeza de Hueyapan, a pesar de tener claros rasgos indígenas, confundió a sus primeros observadores y reforzó la idea de que los primeros pobladores de América eran de raza negra.

Pasados los años, y ya en la tercera década de este siglo, se iniciaron maravillosos hallazgos en la parte sur de la costa del Golfo, y nuevas Cabezas fueron encontradas en La Venta, en San Lorenzo y en Tres Zapotes. Estas y otras esculturas de apariencia humana y animal, que compartían un mismo estilo, suscitaron curiosidad entre los estudiosos del México antiguo, ya que eran totalmente distintas de las creadas por teotihuacanos, aztecas o mayas.

Marshal N. Saville se dio cuenta de que las esculturas mayores y otras de jade en pequeño tamaño, tenían elementos simbólicos comunes, y revelaban un estilo artístico novedoso. Así, afirmó que pertenecían a "la antigua cultura olmeca, la cual tuvo, aparentemente, su centro en el área de San Andrés Tuxtla, alrededor del lago de Catemaco, y se extendió hacia la costa del Golfo de México, en la parte sur del Estado de Veracruz". Gracias a Saville echó raíces el término olmeca; se había establecido, por métodos comparativos, la caracterización de un estilo artístico y de una cultura hasta entonces desconocida.

Las exploraciones arqueológicas continuaron, descubriendo siempre esculturas sorprendentes, pero también edificios, recipientes de barro y de piedra, y pequeños objetos de jade y de serpentina. Estos materiales fueron estudiados por arqueólogos, historiadores e historiadores del arte, y con base en ellos se infirió lo que había sido la cultura: sus costumbres, sus creencias religiosas, sus conductas politicas y sociales, que indicaban el ex-

"Melgar, José María "Antigüedades mexicanas, notable escultura antigua", Boletin de la Sociedad Mexicana de Geografía y Estadistica, Epoca 2, vol I, pp 292.297, México, 1869. "Antigüedades mexicanas, notable escultura", Semanario Ilustrado, México, 1869. "Estudio sobre la antigüedad y el origen de la cabeza colosal de tipo etiópico que existe en Hueyapan, del cantón de los Tuxtlas", Boletin de la Sociedad Mexicana de Geografia y Estadistica, Epoca 2, vol. III, pp. 104-109, México, 1871

${ }^{6}$ Saville, Marshall N. Votive Axes from Ancient Mexico. Monumental Records, vol. I, p. 285. New York, 1929 


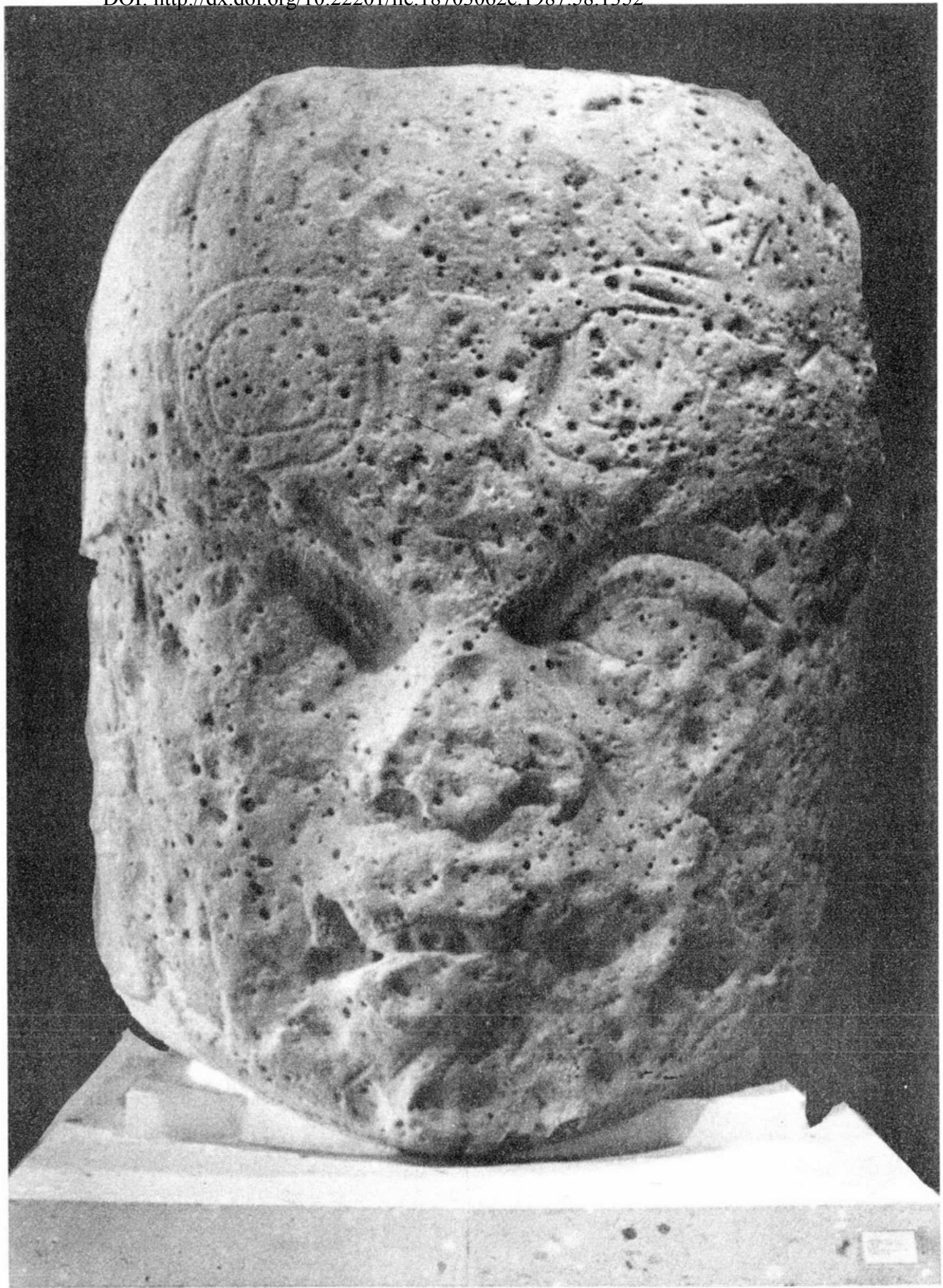

Lámina 1. Cabeza Colosal 7 de San Lorenzo. Museo de Antropología de la Universidad Veracruzana, Xalapa, Veracruz. 


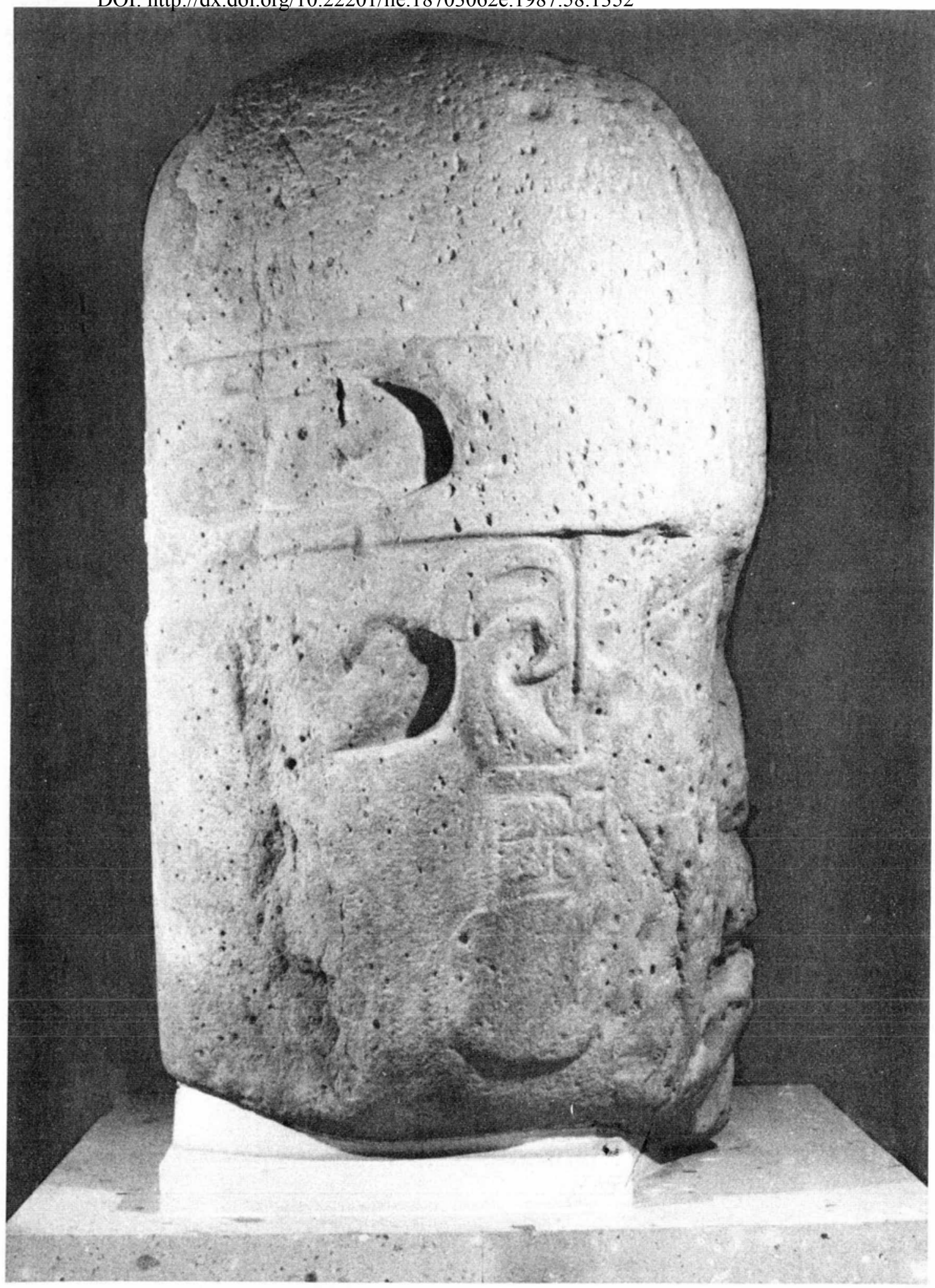

Lámina 2. Cabeza Colosal 7 de San Lorenzo. Museo de Antropología de la Universidad Veracruzana, Xalapa, Veracruz. 


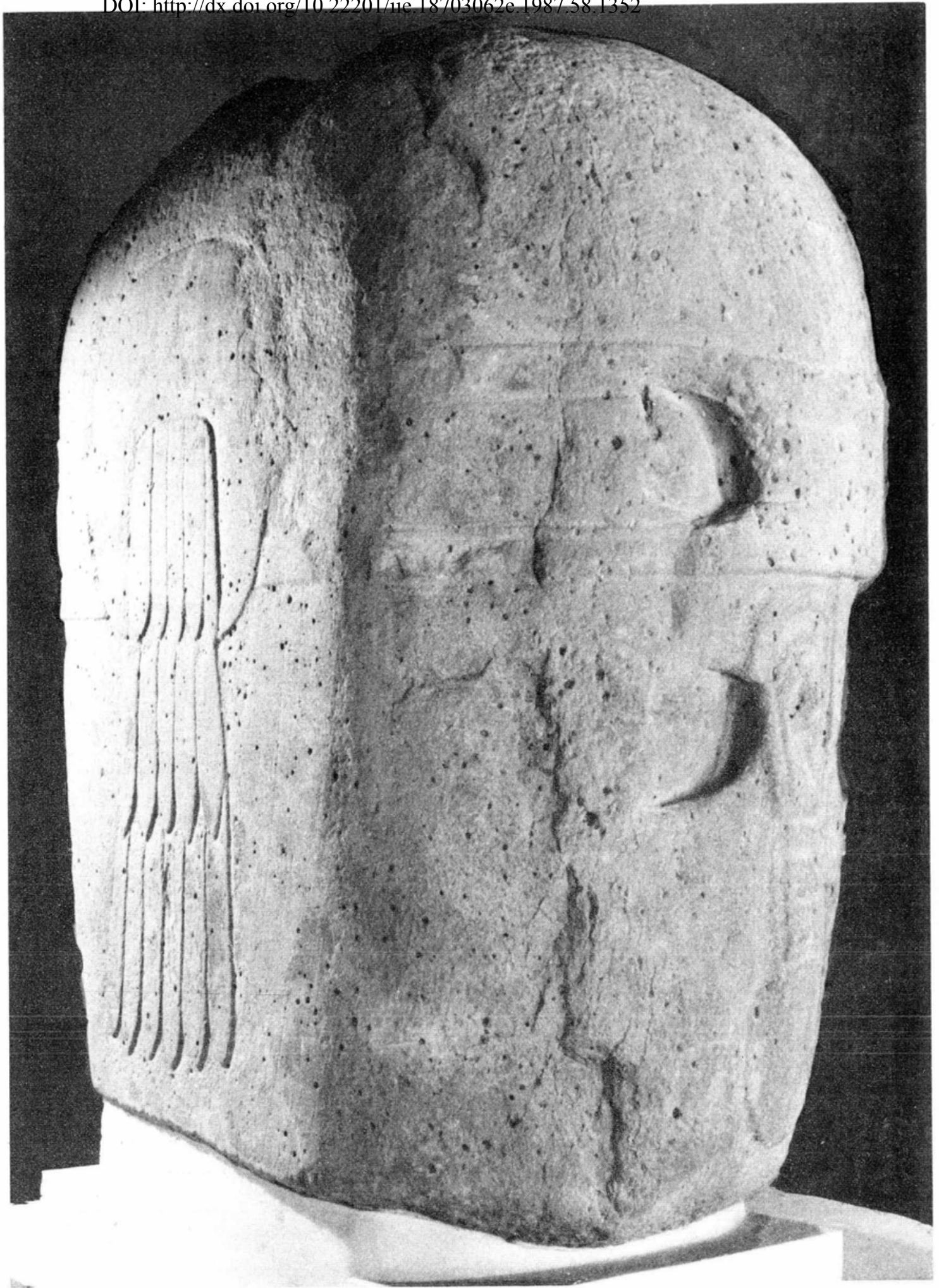

Lámina 3. Cabeza Colosal 7 de San Lorenzo. Museo de Antropología de la Universidad Veracruzana, Xalapa, Veracruz. 


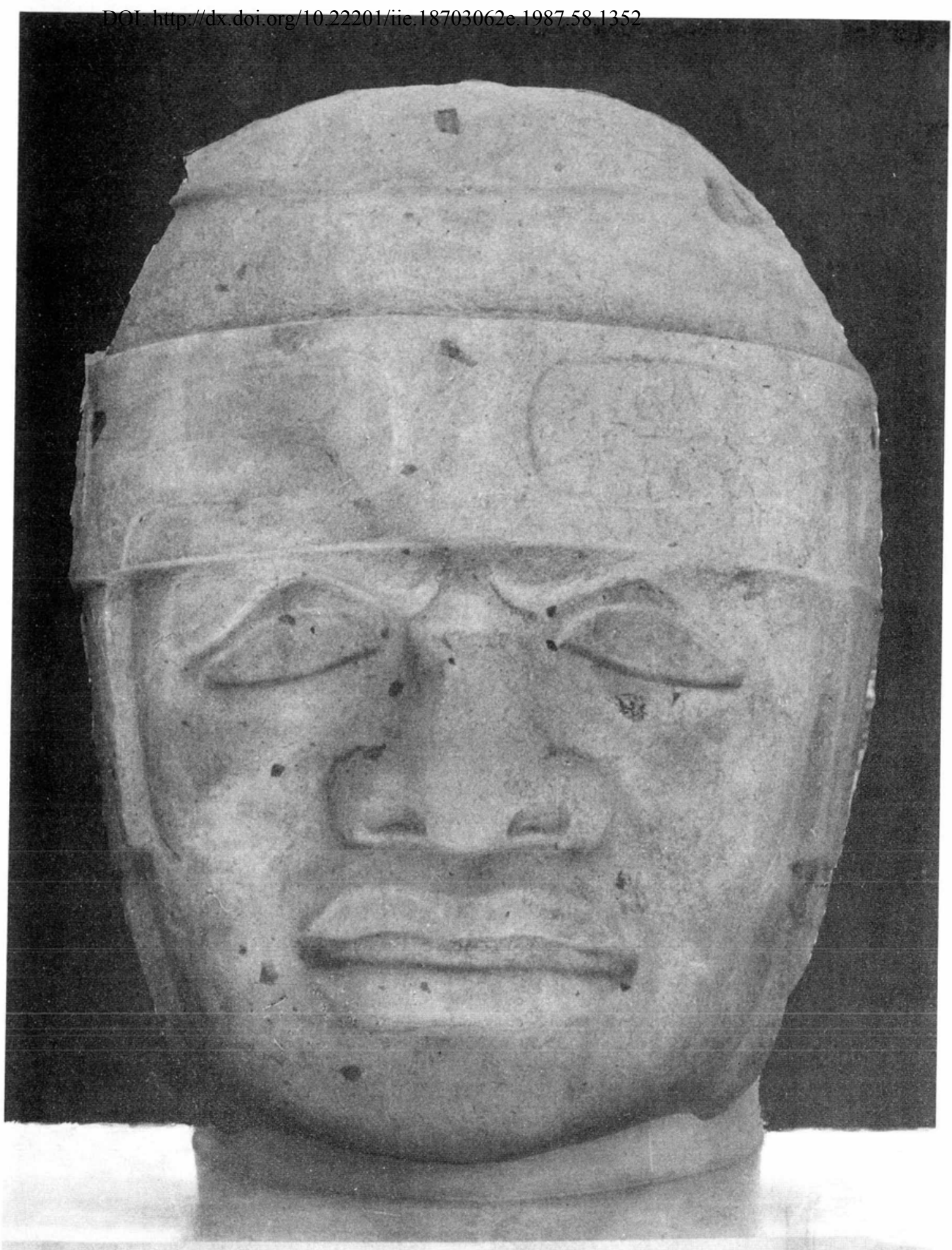

Lámina 4. Cabeza Colosal 8 de San Lorenzo. Museo de Antropología de la Universidad Veracruzana, Xalapa, Veracruz. 


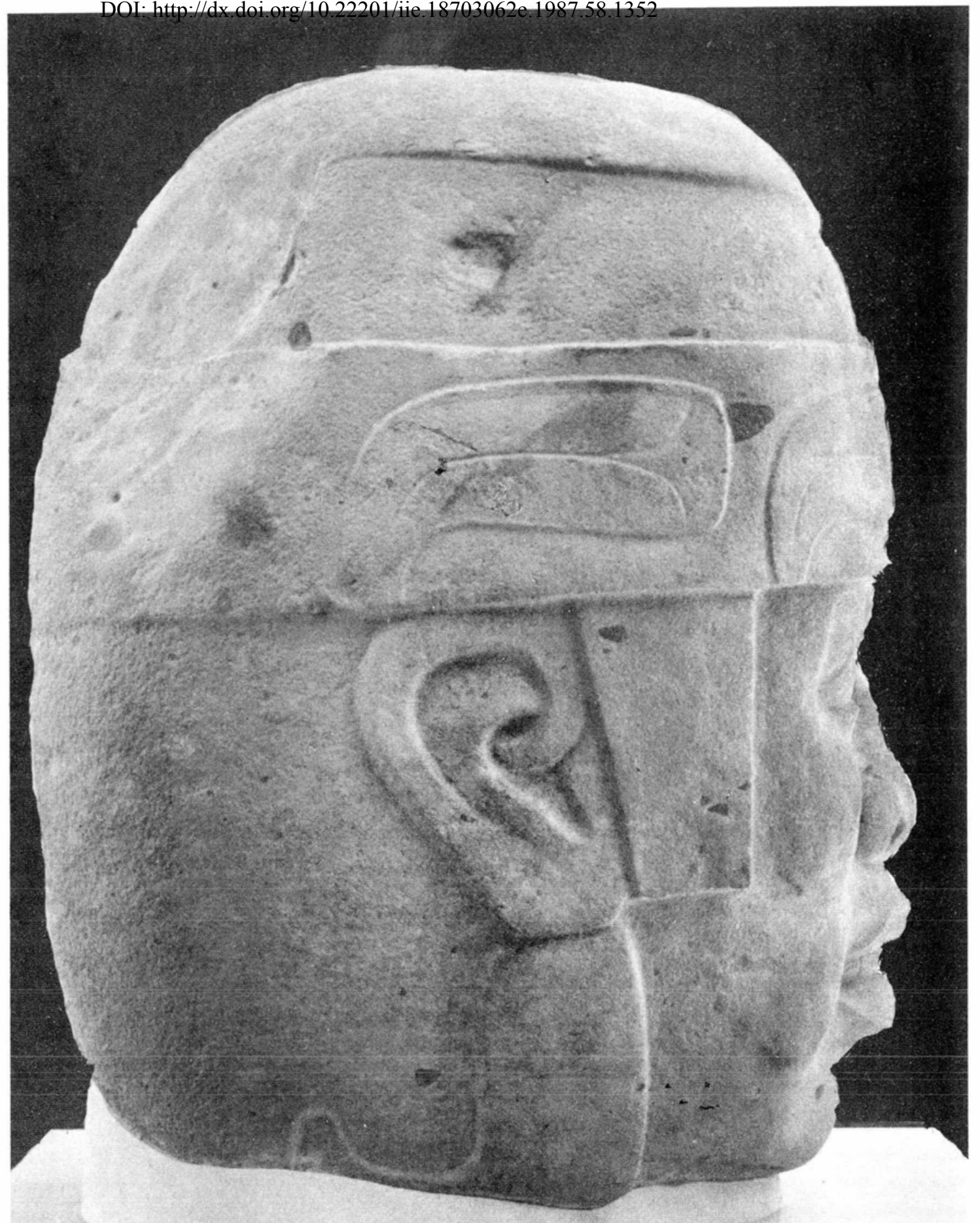

Lámina 5. Cabeza Colosal 8 de San Lorenzo. Museo de Antropología de la Universidad Veracruzana, Xalapa, Veracruz. 


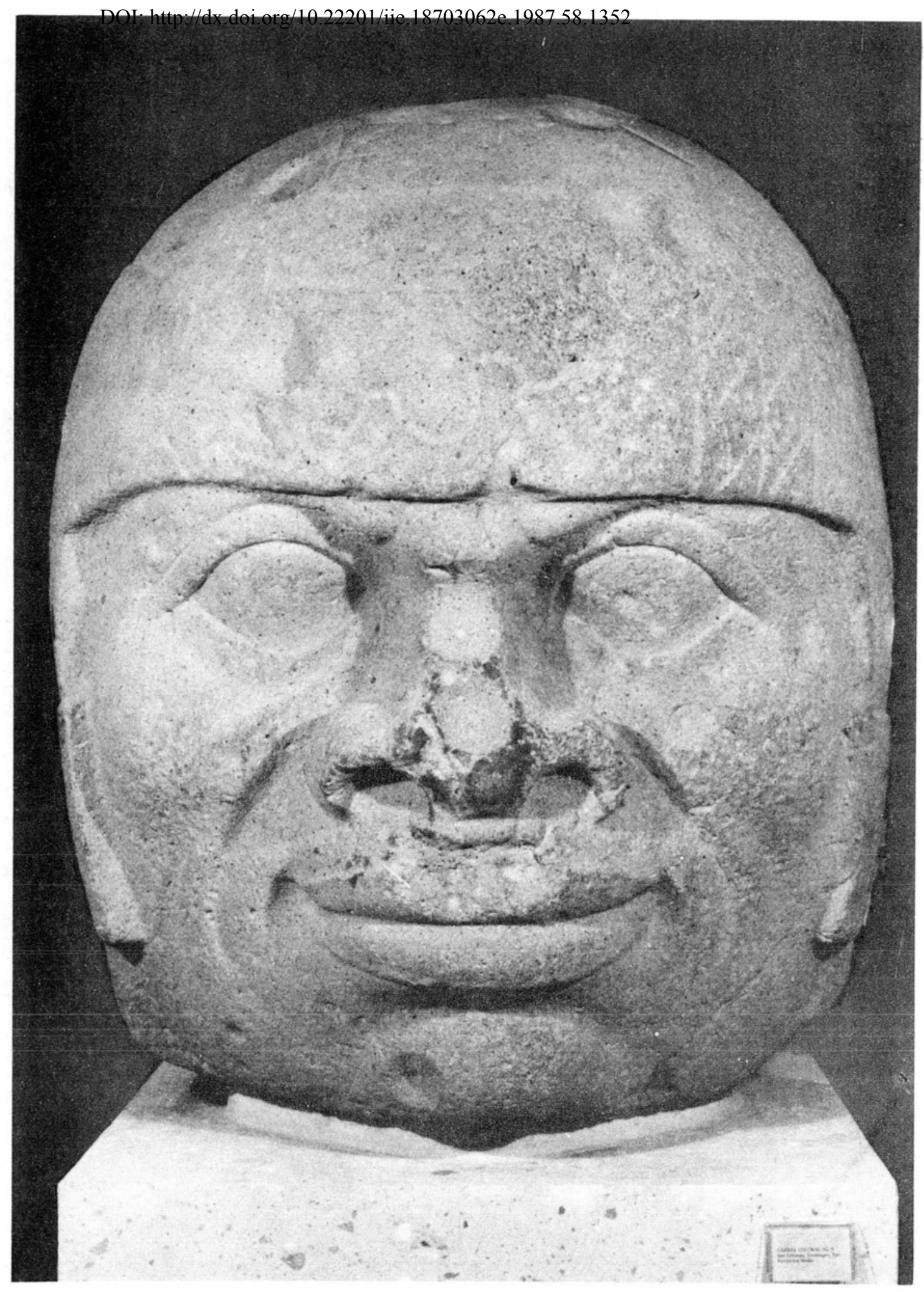

Lámina 6. Cabeza Colosal 9 de San Lorenzo. Museo de Antropología de la Universidad Veracruzana, Xalapa, Veracruz. 


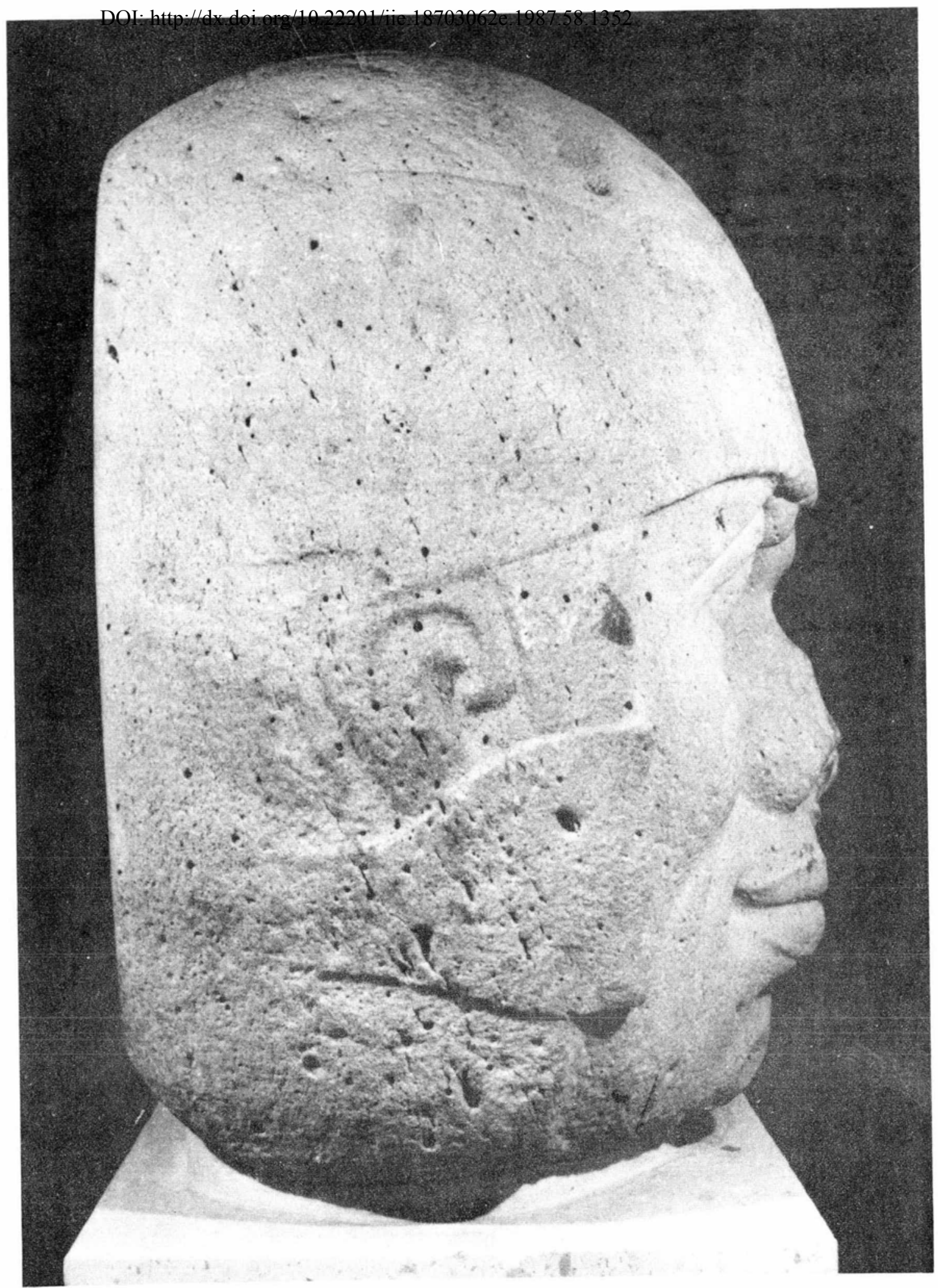

Lámina 7. Cabeza Colosal 9 de San Lorenzo. Museo de Antropología de la Universidad Veracruzana, Xalapa, Veracruz. 
DOI: http://dx.doi.org/10.22201/iie.18703062e.1987.58.1352

$S E C C I O N A$ A REA 


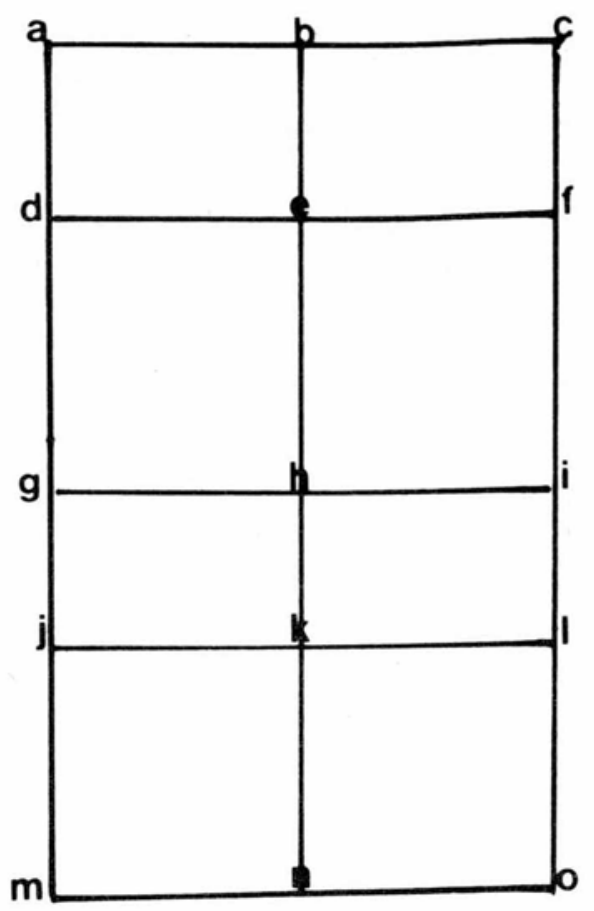

Figura 1. Rectángulo áureo con sus cuatro sobrectángulos internos.

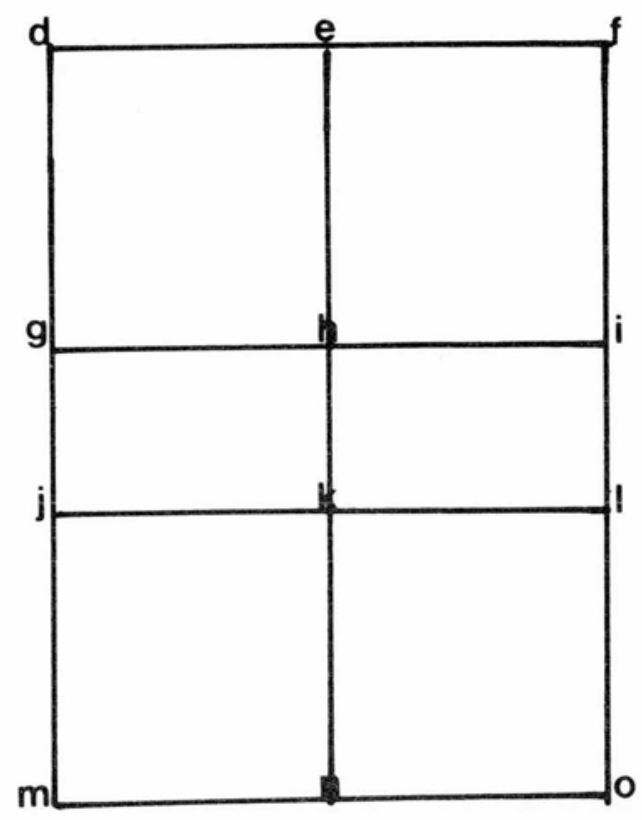

Figura 2. Rectángulo áureo reducido en que se traslapan los cuatro sobrectángulos en la sección media horizontal. 
DOI: http://dx.doi.org/10.22201/iie.18703062e.1987.58.1352

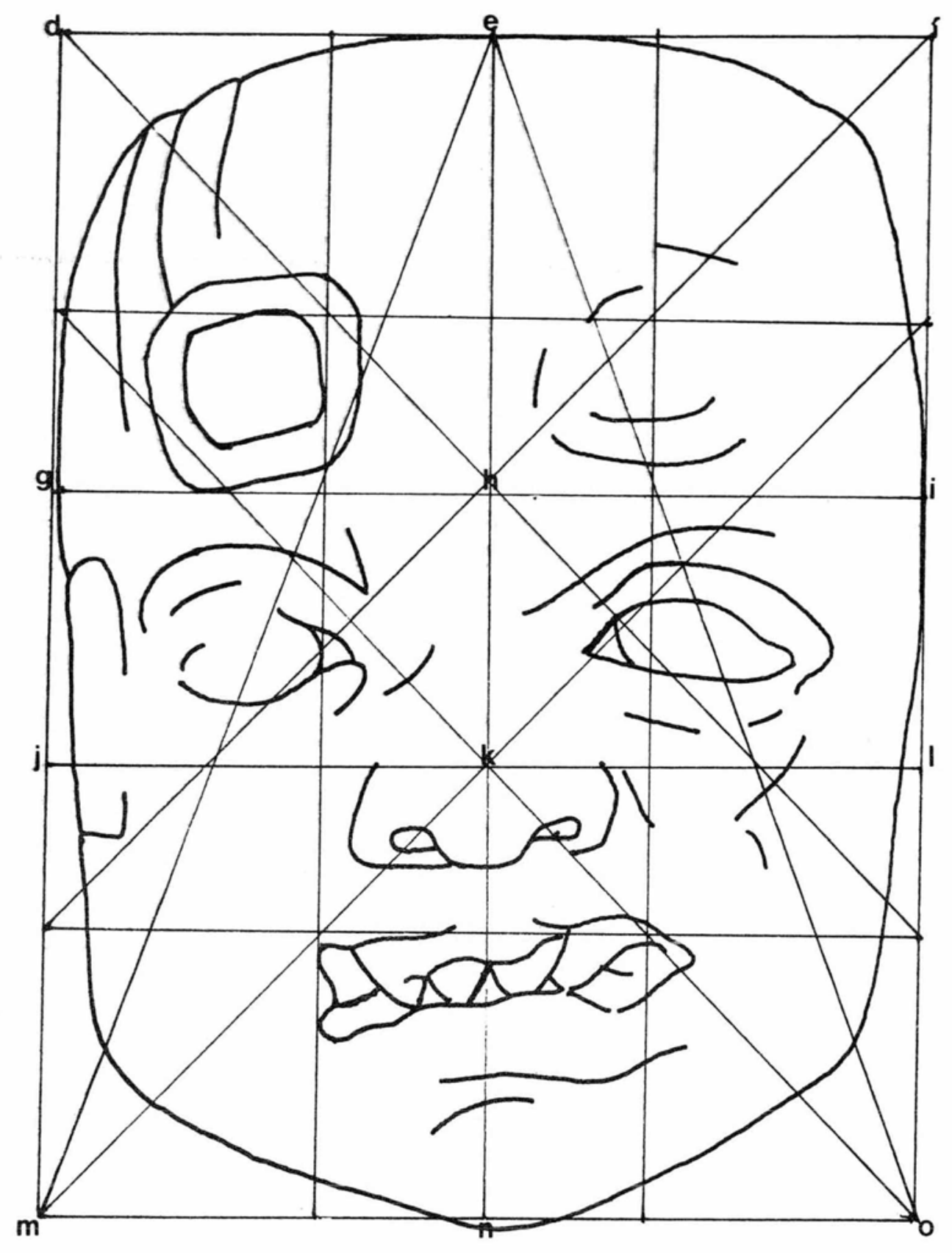

Figura 3. Sección áurea aplicada a la Cabeza 7 de San Lorenzo. 
DOI: http://dx.doi.org/10.22201/iie.18703062e.1987.58.1352

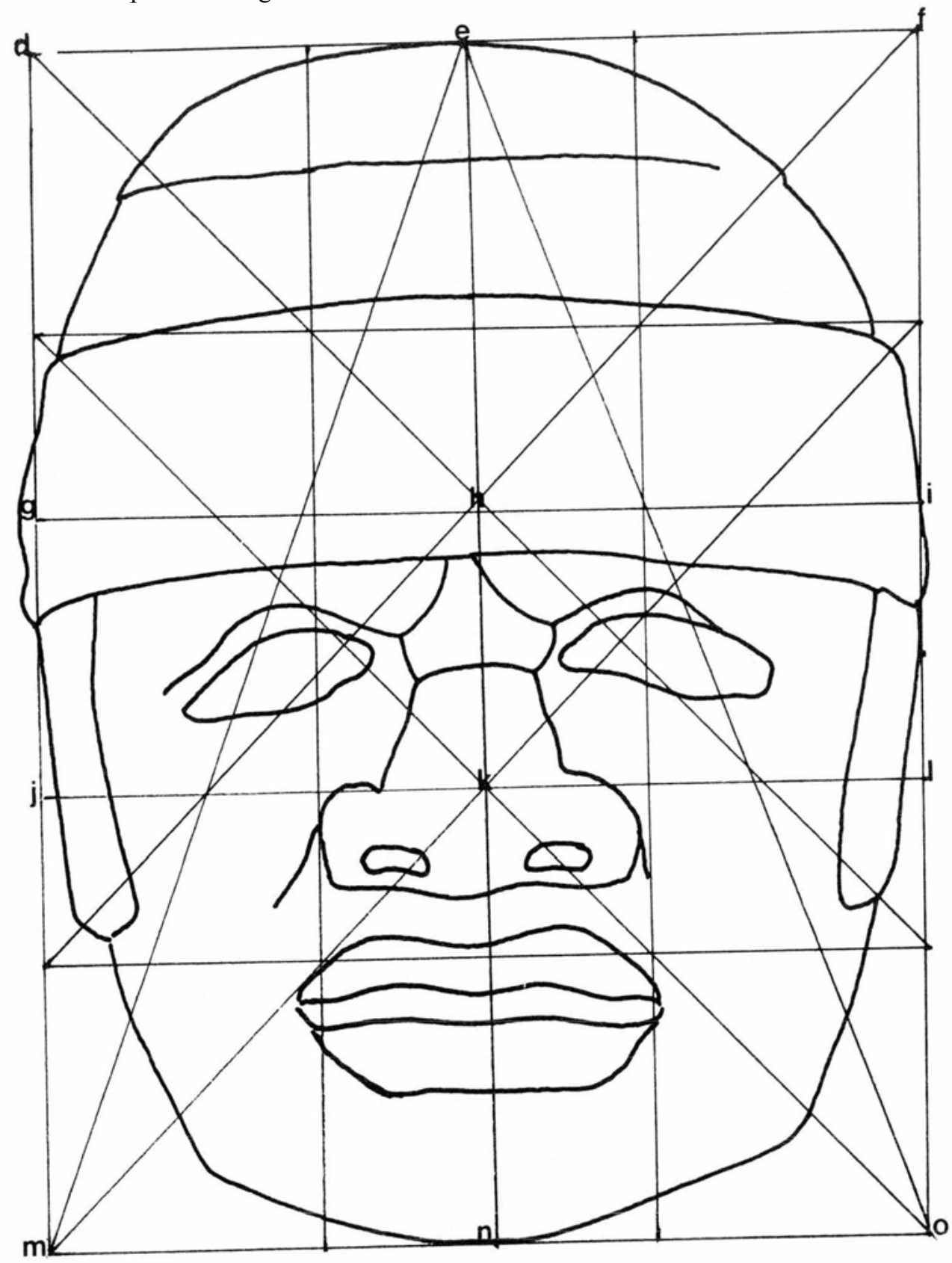

Figura 4. Sección áurea aplicada a la Cabeza 8 de San Lorenzo. 
DOI: http://dx.doi.org/10.22201/iie.18703062e.1987.58.1352

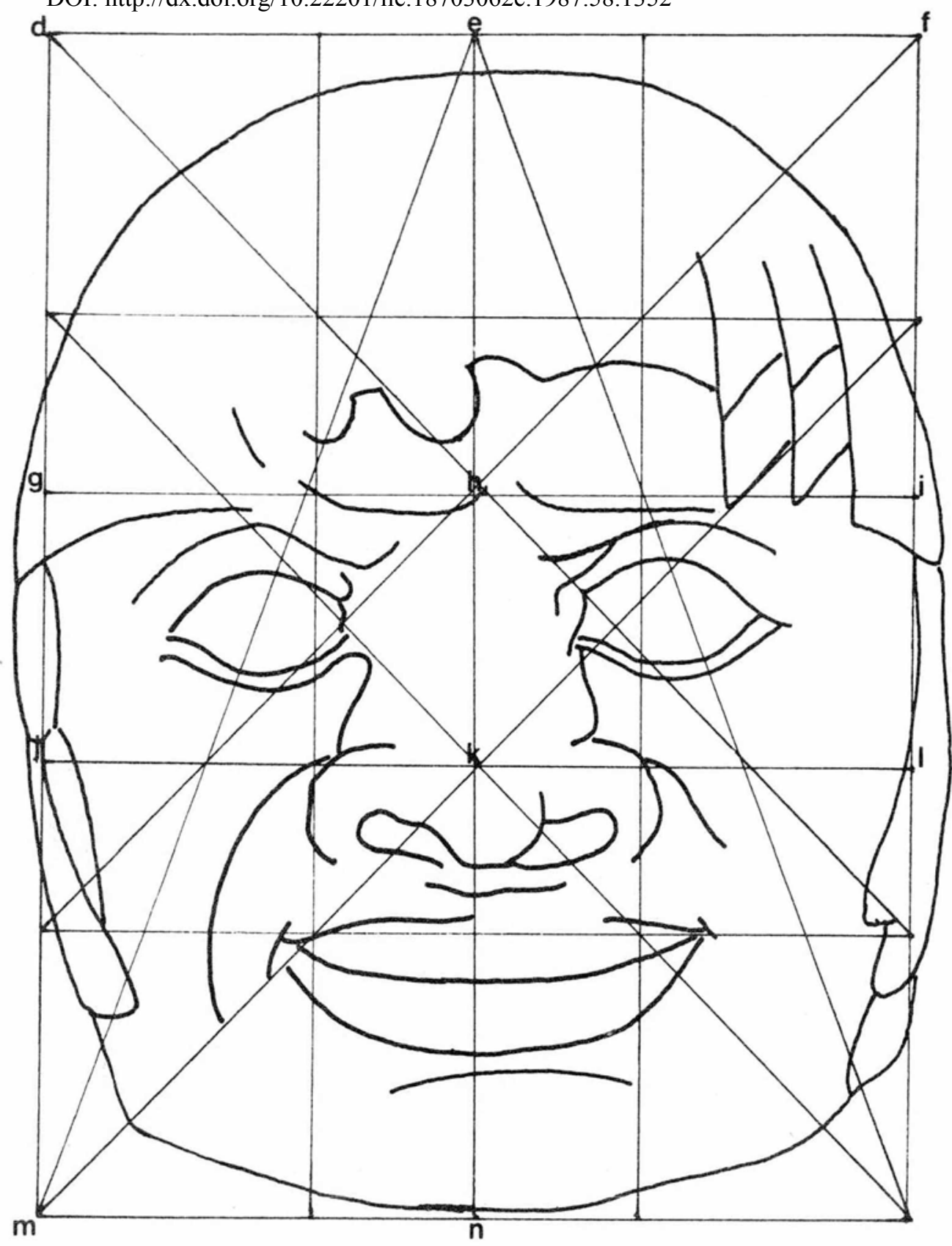

Figura 5. Sección áurea aplicada a la Cabeza 9 de San Lorenzo. 
traordinario avance del hombre en América durante el primer milenio antes de Cristo.

La Venta y Tres Zapotes fueron los primeros sitios olmecas conocidos, luego siguieron San Lorenzo y otros lugares menores; de la comprensión de éstos se concretó por una parte el concepto olmeca; por otra, el concepto se extendió desmesuradamente. Y de esta manera, se llegó a hablar de colonias olmecas en Oaxaca, en el Altiplano de México y, por el sur, hasta en Centro América.

Así las cosas, creo que es tiempo ya de hacer una revisión acerca de lo que es olmeca, del área o de las áreas en donde este fenómeno civilizador se inició, y en cuáles se desarrolló; de las influencias y de su extensión, de su correcta ubicación cronológica y, desde luego, de los símbolos propios del arte olmeca. Sólo a través de una correcta interpretación iconográfica podremos reconocer, con precisión, los objetos de arte olmeca. Por ahora, la expansión del concepto olmeca hacia otras áreas de Mesoamérica ha suscitado afirmaciones erróneas y confusión entre los estudiosos.

La región olmeca de la costa del Golfo ha sido designada "clímax" por los estudiosos extranjeros, y "metropolitana" por los mexicanos; indica la concentración de mayor número de grandes monumentos de piedra; no alude a su origen. Acerca de éste, hay opiniones encontradas; algunos favorecen a la región costera del Golfo, otros se han inclinado por adjudicarla al estado de Guerrero, en donde actualmente se llevan a cabo importantes trabajos arqueológicos en el sitio olmeca antes llamado Teopantecuatitlán, hoy nombrado Tlacosotitlán, trabajos que alumbrarán tan controvertidas opiniones.

Chalcatzingo, en Morelos, en el Altiplano Central, es el sitio que muestra en su escultura mayores semejanzas con la de la costa del Golfo. Me refiero, sobre todo, al Monumento $16 \mathrm{y}$ al Altar de la terraza $25^{7}$; es asombrosa la similitud de éstos con el Monumento 30 y el Altar 4 de La Venta.

Los relieves tallados en la roca indican también semejanza iconográfica con el Monumento 19 de La Venta y con relieves de inconfundible estilo olmeca como la estela de San Miguel Amuco en Guerrero. Con base en tales semejanzas se ha considerado que Chalcatzingo es un sitio olmeca de frontera.

Sin embargo, a pesar de las similitudes escultóricas, Chalcatzingo carece de un elemento fundamental y decisivo en la escultura olmeca: no hay Cabezas Colosales. Estas proceden de La Venta, Tres Zapotes y San Lo-

${ }^{7}$ Grove, David C. Chalcatzingo. Excavations on the Olmec Frontier, p 96, figs 19 y 34, lám. II. Thames and Hudson, 1984 
renzo; es probable que haya más enterradas en algunos de los grandes sitios olmecas de la costa que todavía no se han explorado. Pero Chalcatzingo es un sitio de poca extensión que ha sido explorado casi exhaustivamente, y no parece posible que en el futuro se encuentre una Cabeza Colosal. Y si carece de este rasgo olmeca por excelencia, debido a la importancia primordial de lo que significa en esta cultura, es inadecuado atribuir a Chalcatzingo pleno carácter olmeca.

\section{Hallazgos de las Cabezas Colosales}

La primera Cabeza Colosal, según dije antes, fue encontrada por un campesino, de modo casual, en la hacienda de Hueyapan en 1853; José Melgar la vio en 1862 y dio informe de ella en 1869 y en $1871 .^{8}$ Hoy en día se encuentra en Tres Zapotes.

En 1925, el arqueólogo Franz Blom y el antropólogo Olivier La Farge hallaron la Cabeza 1 de La Venta; de ella dieron noticia en su libro Tribes and Temples. ${ }^{9}$ Se encuentra actualmente en el Parque Museo La Venta en Villahermosa, Tabasco.

Las Cabezas 2, 3 y 4 de La Venta fueron descubiertas durante la expedición conjunta de la Smithsonian Institution y la National Geographic Society, dirigida durante 1939 y 1940 por M. W. Stirling quien publicó fotografías e informó de ellas en 1940 y $1943 .{ }^{10}$ La Cabeza 2 está en el Museo Pellicer, y las Cabezas 3 y 4 en el Parque Museo La Venta, ambos en Villahermosa, Tabasco.

Stirling tuvo la fortuna, además, de descubtir en 1945 las primeras cinco Cabezas Colosales de San Lorenzo. La Cabeza 2 fue el primer monumento encontrado durante la expedición conjunta de la Smithsonian Institution y la National Geographic Society. De la Cabeza 1, Stirling dio amplia razón en un artículo en el National Geographic Magazine en $1947 .^{11} \mathrm{El}$ informe y las fotografías de las restantes se publicaron hasta $1955 .^{12}$ Ac-

8 Ibidem.

9 Blom, Franz y Olivier La Farge. Tribes and Temples. A record of the expedition to middle America conducted by the Tulane University of Louisiana in 1925, p. 85, fig. 76. Tulane University, New Orleans, 1926-27.

10 Stirling, Mathew W. "Great stone faces of the mexican jungle", National Geograpbic Magazine, vol. LXXVIII, pp. 309-334, Washington, 1940.

1i Stitling, Mathew W. "On the trail of La Venta man". National Geograpbic Magazine, vol XCI, pp 137,172,, Washington, 1947.

12 Stirling, Mathew W. Stone Monuments of Rio Chiquito, Verarruz, Mexico Bureau of American Ethnology, Bulletin 157, Anthropological Papers, No. 43, pp 5.23, Smithsonian Institution, Washington, 1955 
tualmente la Cabeza 2 se encuentra en el Museo de Antropología de la ciudad de México, y las Cabezas 1, 3, 4 y 5 se exhiben en el Museo de Antropología de la Universidad Veracruzana en Xalapa, Veracruz.

No se sabe la fecha exacta del hallazgo de la Cabeza 6 de San Lorenzo; fue accidentalmente descubierta por campesinos. Es el Monumento 17 , y fue reportada por primera vez en 1965 por L. Aveleyra. ${ }^{13}$ Se exhibe en el Museo de Antropología de la Ciudad de México.

Acerca de las otras tres Cabezas de San Lorenzo, las 7,8 y 9 que hoy se conservan en el Museo de Xalapa, hice mención al principio de este artículo.

Sobre la Cabeza 1 de Nestepe (también llamado Monumento 2 o Monumento $\mathrm{Q}$ de Tres Zapotes) se ignora cuándo fue, casualmente, descubierta por campesinos durante el desmonte de un área de palmas en Cerro Nestepe. T. Smith la publicó en 1963, y se encuentra en el Museo de Santiago Tuxtla, Veracruz. ${ }^{1+}$

Al arqueólogo Francisco Beverido le estaba destinado reportar la Cabeza de Cobata, en 1970, cuando él y el arqueólogo norteamericano R. Squier tenían a su cargo el Proyecto Olmeca de los Tuxtlas; se encontraba ente-. rrada en un nivel superficial de la ladera del Cerro El Vigía. Se dio infor. me de ella en $1973 .{ }^{15}$ Hoy en día está en la plaza de Santiago Tuxtla, Veracruz.

\section{Cabeza Colosal 7 (Láms. 1, 2 y 3)}

Tallada en basalto, mide $270 \mathrm{~cm}$ de alto, $185 \mathrm{~cm}$ de ancho y $135 \mathrm{~cm}$ de espesor; pesa 18 toneladas. Es, de todas, la más dañada en su vista frontal, tanto por los numerosos hoyos de diferentes tamaños y las acanaladuras profundas causadas por mutilación intencional en tiempos olmecas, como por los efectos de la intemperie. Así, su estado de erosión es irreparable. Está también quebrada de la nariz, los labios, la barba y las mejillas. Su lamentable condición se explica porque descansó con el rostro hacia arriba, durante siglos, a escasos $40 \mathrm{~cm}$ de profundidad, de modo tal que la frecuente lluvia del lugar se filtraba fácilmente y desgastaba la piedra en forma constante. Esta posición que perjudicó tanto su vista

${ }_{13}$ Aveleyra Arroyo de Anda. "Una nueva cabeza colosal olmeca", Boletin del Instituto Nacional de Antropología e Historia, No. 20, pp. 12-14, México, 1965.

${ }^{14}$ Smith, Tillie. "The main themes of "Olmec" att Tradition", Kroeber Antbropological Society Papers, No. 28, pp. 121-213, Betkeley, 1963

15 Fuente, de la, 1973, p 124. 
frontal, hizo posible la conservación de la parte posterior, en donde se labró, con suma precisión, un vistoso adorno de plumas.

Las secciones carcomidas y las partes faltantes le otorgan una peculiar expresión de fiereza, que se acentúa por los destrozados labios entreabiertos mostrando los dientes como si hubieran sido limados en forma de $V$. Sus almendrados ojos son grandes y están muy abiertos, como si quisieran reproducir la mirada alerta del retratado. Los iris, próximos a las comisuras internas, señalan su estrabismo; son discos relevados, círculos de perfección inmutable, simbolizadores del mundo espiritual, invisible y trascendente. Rebordes curvos que se engruesan en la parte media superior del ojo y disminuyen su grosor a medida que descienden hacia las comisuras, forman los párpados superiores. A pesar del deterioro, se advierte que los párpados fueron carnosos. Parece que originalmente lució, al igual que la Cabeza 5 del mismo lugar, una superficie bien modelada en torno a los ojos, ya que proporciones de las órbitas y los lagrimales se miran suaves pero profundamente rehundidos. Planas son las extendidas mejillas, y el mentón desciende perceptiblemente por abajo del maxilar inferior.

Una banda y un casquete hemisférico forman su tocado; aquélla se orna* menta al frente por dos grandes anillos incisos; el casquete parece haber sido liso. En la vista posterior de la Cabeza un enorme disco en relieve ocupa, al centro, parte del casquete, toda la banda y una porción por abajo de ésta. De su parte media desciende un adorno vertical de tres haces de plumas colocados uno abajo del otro; el más alto y el de parte media se forma por cinco plumas, el inferior lleva seis. No hay otro ornamento igual en los tocados de las Cabezas Colosales.

Las pequeñas orejas se pegan a la cabeza; de ellas se mira el pabellón estilizado en doble contorno de espiral; el lóbulo se cubre por grandísimos pendientes, compuestos por una sección superior que se forma, arriba, por una banda horizontal; dos placas, también horizontales, componen la parte media; una de éstas es más larga que la otra; en la parte baja se miran dos placas menores, una rectangular y la otra de silueta inferior curva; en el interior de ésta se advierte un pequeño orificio circular. Bajo esta sección el pendiente se convierte en gran disco en relieve.

Cabeza Colosal 8 (Láms. 4 y 5)

Tallada en basalto, mide $220 \mathrm{~cm}$ de alto, $165 \mathrm{~cm}$ de ancho y $160 \mathrm{~cm}$ de espesor; pesa 12 toneladas. Su casi perfecto estado de conservación hace difícil pensar que fue tallada antes del primer milenio de nuestra Era. Sólo 
se le aprecian cinco concavidades, de tiempos olmecas, en la parte alta y en la vista posterior. Muestra, además, algunas acanaladuras en la porción superior de la cabeza, cerca de donde se abre el casquete para dejar pasar lo que pudieron ser mechones de pelo. Algunas irregularidades en la piedra, en la vista trasera, permiten suponer también que fue golpeada en tiempos remotos.

Sin embargo, no es sólo el excelente estado que conserva, sino la purísima y precisa calidad de la talla y el orden absoluto de su proporción armónica lo que le confiere, a mi juicio, primacía entre las Cabezas Colosales. Por ello, posiblemente, se le otorgó lugar de preferencia en el nuevo Museo; está colocada en el gran vestíbulo, directamente frente a la entrada principal.

Es, entre las de San Lorenzo, la que muestra mayor aspecto de bloque; su gran espesor, el mayor de todas las Cabezas, refuerza perceptiblemente esta cualidad volumétrica. La vista posterior carece de labrado, pero se curva y acentúa su carácter tridimensional. Tal rasgo de forma la distingue de otras de San Lorenzo, las más estrechas de las cuales son la 3 y la 4; esta última alcanza apenas $95 \mathrm{~cm}$.

De todas las Cabezas Colosales, las de espesor más grande son, aparte la de Cobata, las de Tres Zapotes, en particular la de Nestepe, que en ese sentido mide, como la de San Lorenzo $8,160 \mathrm{~cm}$.

$\mathrm{Su}$ condición de volumen le confiere asimismo notoria sensación de gravedad.

Sus rasgos, vistos de perfil, se advierten nítidamente perfilados; de frente destaca, sobre todo, por su modelado. Así, el entrecejo se forma con dos abultamientos separados entre sí; los grandes ojos en forma de almendra, están claramente delineados y se miran con las comisuras externas redondeadas y caidas. A su vez, las comisuras interiores, junto al lagrimal, se ven apuntadas. En la superficie del globo ocular, los iris revelados ocultan porciones entre los párpados de modo tal que no se aprecia su disco completo. Muestran acentuado estrabismo.

Los párpados superiores son levemente apuntados y marcan un pliegue carnoso. En los inferiores se percibe también suave prominencia quie baja y se rehunde para abultarse notablemente en las mejillas, que luego se remeten hacia abajo, vuelven a levantarse a la altura del labio inferior, y finalmente cuelgan y se continúan con la superficie del mentón.

Es tal la plenitud de su modelado, que reproduce de manera fiel la blandura carnosa de las mejillas del retratado.

La nariz, corta y ancha, enseña una ondulación en el dorso, alas perfiladas por una línea curva y amplias fosas dibujadas con precisión. La boca, 
grande y sensual, es de labios arqueados con un resalte en sus bordes; está ligeramente abierta y deja ver los dientes.

La perfección anatómica se advierte también en el modelado por encima del labio superior, en la discreta proyección de éste y en el leve rehundimiento que se forma por abajo del labio inferior.

En efecto, la Cabeza 8 es, lo dije antes, excepcional en su factura; el maestro que la talló, recreó con habilidad sor prendente el rostro maduro de su modelo. Para ello, combinó líneas, cuando era necesario perfilar, y prominencias y rehundimientos cuando se requería mostrar los abultamientos faciales.

El tocado se compone de dos bandas y un casquete. La banda inferior, ceñida sobre el entrecejo, lleva un diseño repetido en cuatro ocasiones, consistente en una faja que se bifurca en dos lengüetas planas y redondeadas; a este diseño se le ha llamado "ala de golondrina" y se encuentra, según Joralemon ${ }^{16}$ limitando los símbolos incisos en el rostro de la figura de Las Limas. La banda superior es lisa y remetida; el relevado casquete lleva al centro de su parte alta 6 tiras paralelas; pudieran representar mechones de cabello. Al frente de las orejas, cuelgan dos bandas protectoras.

De los rasgos faciales, sólo las orejas se representaron de manera simplificada y reducidas, de modo abstracto, en sus componentes esenciales; así, el pabellón es una doble espiral y el lóbulo una superficie plana. Bajo éste se prenden grandes pendientes en forma de gancho, iguales a los que lleva San Lorenzo 5 -orejeras similares usan también San Lorenzo 4 y La Venta 2-, la cual muestra en el tocado dos garras compuestas por tres dedos: son garras de ave de presa.

Acaso la relación de la llamada "ala de golondrina" con las garras no sea ajena a la identidad del personaje retratado.

De las Cabezas de San Lorenzo, la 5 y la 8 son las que guardan mayor semejanza formal en su modelado, de modo tal que sus cualidades táctiles las destacan, sensiblemente, de las demás.

El parecido formal y simbólico sugiere, por una parte, que las labró el mismo maestro o que proceden de un solo taller de cantería; por otra, su posible relación simbólica permite suponer que se trata de personajes con vínculos de linaje dinástico.

Ciertamente, la Cabeza 8 muestra en su rostro firmeza, autoridad y poder; lleva, como dotación natural, la noble calidad del señorío.

${ }_{16}$ Joralemon, Peter D "A stduy of Olmec bibliography", Studies in precolumbian art and archaeology, No. 7, pp. 17, 20 y 21, Dumbarton Oaks, Washington, 1971 


\section{Cabeza Colosal 9 (Láms. 6 y 7)}

Más pequeña que las anteriores, la Cabeza 9 mide $165 \mathrm{~cm}$ de alto, $136 \mathrm{~cm}$ de ancho y $117 \mathrm{~cm}$ de espesor. Se le ha llamado "personaje con sonrisa", y en efecto, sus apretados labios de comisuras hacia arriba, marcando visiblemente las arrugas producidas por la contracción, le otorgan apariencia sonriente. Su expresión no es única entre las Cabezas Colosales; La Venta 2, por lo que se conserva de sus labios mutilados, parece esbozar una sonrisa.

Aunque la cabeza 9 permaneció algún tiempo en una suerte de lecho de lodo y mirando hacia arriba, no sufrió daños considerables, ni presenta huellas que alteren su fisonomía, salvo ciertos hoyos en la nariz, en la barba y en el tocado, leves quebraduras en la nariz, desprendimiento de capas de piedra en la mejilla, y una fractura, aparentemente superficial, que baja en diagonal del pendiente hasta el mentón.

El rostro tiene apariencia negroide; recuerda a La Venta 4 y a Nestepe o Tres Zapotes 2; su diferencia con ellas estriba en que estas últimas son prógnatas. La fisonomía de las tres parece distinta a la de nuestros antepasados indígenas.

También se vincula en sus formas, por el juego de las curvaturas en el rostro, con las Cabezas 5 y 8 de San Lorenzo; depresiones y prominencias, superficies cóncavas y convexas, originan una dinámica de luces y sombras que contrarresta el estatismo natural a la magnitud del volumen.

El ceño es abultado y fruncido, los ojos, en forma de almendra, son muy grandes y resaltados; sus comisuras terminan en punta: las exteriores están ligeramente inclinadas hacia abajo. La línea bien perfilada del párpado superior traslapa la del inferior, y los iris, circulos perfectos, se advierten apenas relevados y exhiben notorio estrabismo. La nariz es aplastada, de alas anchas y grandes fosas.

Pronunciadas son las mejillas a la altura de los pómulos; al descender se remeten, para ampliarse sobre los maxilares mostrando así la anchura del rostro. Surcos profundos se advierten a los lados de la nariz y de las comisuras de los labios; le otorgan su fisonomía sonriente por la marcada contracción muscular.

Los labios muy juntos, apretados, se miran divididos por una línea en cuyos extremos se tallaron sendos hoyuelos que contribuyen a su expresión suave, casi amable. Su mentón es pronunciado.

Pequeñas orejas pegadas a la cabeza, muestran la doble espiral del pabellón; los lóbulos quedan parcialmente cubiertos por enormes pendientes constituidos por anchas tiras horizontales y grandes formas abocinadas, similares a las que aparecen en Tres Zapotes 2. 
Un casquete hemisférico es el tocado; sólo se aprecia al frente y a los lados; la parte posterior es plana. De su diseño se advierten, en el lado izquierdo, bandas paralelas verticales con líneas diagonales en su interior; recuerdan cordones enrollados y se asemejan a los tocados de San Lorenzo 3 y 4; por el lado derecho y en el centro, permanecen restos de un diseño ondulado. Frente a las orejas bajan dos bandas cortas que reproducen las que, acaso, sirvieran para asegurar los sombreros y protegerse las orejas.

Parece reiterativo insistir en la individualidad de los rostros de las Cabezas Colosales; la 9 de San Lorenzo que ahora ilustro cabalmente por primera vez, es nuevo testimonio de singularidad por su excelencia artística que plasma tanto la condición temporal humana como su posible eternidad.

\section{Sobre la proporción armónica en las Cabezas} Colosales 7, 8 y 9 de San Lorenzo

Cuando me aboqué a encontrar en las Cabezas Colosales el principio armónico de proporciones que determina su unidad formal, quedaron fuera de mi estudio las Cabezas 8 y $9 .{ }^{17}$ La primera ya había sido hallada, pero permanecía recostada de lado en su lecho de tierra, y no era apreciable en su vista frontal. De la segunda no se tenían noticias.

La Cabeza 7, que para entonces ya se había descubierto, pero que permaneció enterrada después de la exploración arqueológica, pudo fotografiarse porque mantenía el rostro hacia arriba. A ésta, debido a que su fotografía no fue tomada cabalmente de frente, le apliqué un sistema de proporción armónica diferente del que ahora presento.

Ahora bien; aunque es sabido de todos los historiadores de arte en qué consiste este sistema de proporción armónica, considero conveniente recordarlo, de manera breve, para clarificar mi exposición y justificar el lugar que, de acuerdo con dicho sistema, le corresponde a las Cabezas Colosales de que ahora trato.

Ũn rectángulo de sección áurea consiste en un cuadrado (prmo, fig. 1) y una sección rectangular (acpr, fig. 2), cuya altura guarda la proporción de 1.618 en relación con la medida total de los lados de dicho rectángulo. Ese rectángulo puede a su vez dividirse en cuatro menores (abgh, bchi,

${ }^{17}$ Fuente, Beatriz de la, "La proporción armónica en la escultura monumental olmeca", Actes du XLIIe Congrès International des Améticanistes, vol. VII, pp 337-356, París, 1980. 
ghmn y hino), necesariamente áureos también y, por lo mismo, compuestos de un cuadrado y una sección proporcional (fig. 3).

¿Por qué un rectángulo con esa proporción y dividido así produce sensación de equilibrio? Desde luego, los subrectángulos originados por el cruce de $\emptyset$, son entre sí proporcionales y rítmicos de medidas; la medida $\emptyset$ (1.618) es básica en las proporciones de nuestro cuerpo, en las de muchos animales, en plantas y formaciones de infraestructura de la materia viva y en expansión formativa; es una de las cifras claves de la constitución de la materia.

Una cabeza humana de proporciones tigurosamente clásicas, vista de frente, puede inscribirse en un rectángulo de proporciones áureas cuyo lado menor equivale a la anchura del rostro, considerada a nivel de los ojos, y el mayor ocupa su largo total, desde el mentón hasta el vértice de la cabeza.

Al aplicar este sistema de proporciones a las Cabezas Colosales olmecas, consideradas como una unidad que incluye el tocado que lleva, se obtuvieron, en el estudio a que hice referencia, ${ }^{18}$ tres grupos principales y dos subgrupos. El primero está constituido por la Cabeza 4 de San Lorenzo, la única que permite su inclusión en el rectángulo completo con su cuádruple división ${ }^{19}$; es el rectảngulo áureo de relación igual a 1.618 , el canon de oro perfecto.

El segundo grupo está compuesto por aquellas Cabezas que quedan inscritas dentro de un rectángulo áureo compuesto por cuatro rectángulos de las mismas relaciones armónicas y que se traslapan en la parte media central, de modo que en el rectángulo total falta la sección horizontal correspondiente superior, sección que en realidad existe sobrepuesta en la parte media. Dentro de tal patrón quedan las Cabezas 1,3 y 5 de San Lorenzo y la 2 de La Venta. En este grupo se incluyen ahora las Cabezas 7 , 8 y 9 de San Lorenzo. Con ello, es dable suponer que fue el patrón más usado en San Lorenzo, y que su vigencia se debió, posiblemente, a que era del conocimiento de los maestros y su taller de cantería; el patrón se aplicó en el lapso durante el cual se talló el mayor número de Cabezas de ese sitio.

Un subgrupo de esta división incorpora a La Venta 1 y a Nestepe; aunque se adaptan al canon descrito, muestran diferencias tales como que rebasan en toda la extensión de sus lados verticales el rectángulo armónico.

\footnotetext{
18 Ibidem.

${ }^{19}$ Ibidem, fig 3
} 
El tercer y último grupo se caracteriza porque ya no se adaptan al rectángulo áureo; no hay en las Cabezas que lo integran, estructura armónica que determine su composición. Aquí se ubican la 1 de Tres Zapotes y la de Cobata.

El esquema de composición de las Cabezas 7,8 y 9 de San Lorenzo es el mismo para las tres; se trata de la articulación de cuatro rectángulos de oro sobrepuestos en la parte media, en la sección que corresponde a la parte entre la línea horizontal ( $\mathrm{g} i$ ), que va a la altura o un poco por arriba del reborde inferior del tocado, y la línea ( $j l$ ) también horizontal, que pasa sobre las alas de la nariz.

\section{Cabeza Colosal 7 (fig. 4)}

Su inscripción en rectángulo áureo (dfmo) es total; de hecho, la parte superior del casquete corre casi paralela a la línea (dj), y el punto (e) señala con exactitud el centro superior. A la altura de los pendientes el rostro disminuye su anchura, de modo tal que baja y se inclina hasta el punto ( $n$ ) en el mentón. Tal punto forma, al unirse con el punto superior (e), el eje vertical medio del rostro. La cabeza así dividida en dos secciones revela ciertas irregularidades; las dos mitades no son del todo simétricas. De este modo, el ojo derecho se advierte más bajo que el izquierdo, y la boca se prolonga más en su lado derecho. Ciertamente, los ejes resultantes de las secciones áureas convergen en puntos de particular interés plástico del rostro: el $(h)$ se sitúa entre los pliegues carnosos del entrecejo; el $(k)$ señala la parte media del dorso de la nariz. Es notable, en la asimetría perceptible por los trazos de los ejes, que el estrabismo es más acentuado que en otras cabezas, y que los iris no conservan entre sí la misma cercanía con el lagrimal.

Aun cuando existe correspondencia de los rasgos físicos representados con los puntos cruciales de la composición armónicâ, no se advierten plenamente coincidentes. Por ello debe recordarse su mal estado de conservación, que altera la apreciación armónica.

\section{Cabeza Colosal 8}

Sin duda es la más perfecta de este grupo de composición armónica. Se incluye cabalmente en el rectángulo (dfmo); los puntos $(e)$ y $(n)$ señalan, con exactitud, el punto medio superior y el punto medio inferior, 
puntos que al unirse por una línea, el eje vertical medio, destaca la clara simetría de las dos partes en que se divide el rostro. Sólo es equiparable en su precisión armónica con San Lorenzo 4. Los puntos que indican la pureza de la composición, revelan también los puntos radicales del rostro. Así, el punto $(h)$ marca la unión del entrecejo cubierto por la banda del casquete, y el punto $(k)$ señala la parte central del dorso de la nariz. Las líneas que se cruzan sobre los iris indican la convergencia bilateral de su estrabismo; no deja de sorprender que el cuadrado formado por los puntos del entrecejo $(h)$, el punto central de la nariz $(k)$ y los ángulos que se construyen con las líneas que marcan el estrabismo, coincida precisamente con esa parte del rostro que expresa concentración profunda.

No es casual, a mi modo de ver, la presencia de un cuadrado que resulta de los puntos y ejes de los trazos de la composición áurea; un rostro de tal orden y perfección tiene que revelar en la relación de sus rasgos faciales símbolos de orden universal. Así, el cuadrado con sus cuatro rectas iguales que forman cuatro ángulos en el entrecejo, la nariz y los iris va de acuerdo, en su estabilidad, con la expresión serena que emana de la intensa concentración. Las Cabezas Colosales se miran animadas porque reproducen, con fidelidad, personajes reales; pero la estructura que las conforma se ancla en este cuadrado central que implica la idea de detención, simboliza la permanencia o el instante contenido. Así, son retratos que en su estructura interna guardan símbolos referidos a la fijeza de lo terrenal. Hay, sin embargo, otro aspecto simbólico digno de consideración: los cuadrados que indican la parte inmóvil y de sostén se inscriben en los curvos límites de una figura más o menos oval que corresponde a la Cabeza. Esta figura es variable en sus porciones superior e inferior; pero el casquete del tocado de contorno semicircular recoge en su centro el cuadrado antes mencionado. Por ello se crea una tensión equilibrada entre la quietud del cuadrado terrenal y la circularidad dinámica de lo espiritual.

\section{Cabeza Colosal 9}

No muy distinta a la anterior, en lo que toca a su proporción armónica, es la Cabeza 9. Rebasa con el tocado las líneas verticales del rectángulo. Hay, asimismo, correspondencia entre la estructura geométrica y la realidad formal. De esta manera, se complementa, por su curvatura, la base del rostro con el casquete del tocado. Punto principal es el de la parte central superior del casquete (e), un poco por encima de éste, que al formar eje 
con el punto $(n)$ realiza los efectos plásticos de toda la sección media vertical. Las dos mitades que resultan de tal eje se miran discretamente asimétricos; el ojo izquierdo es más bajo que el derecho, y la nariz más amplia en su ala derecha.

Su expresión sonriente y apacible se debe, en buena medida, a la reposada vertical que se extiende por el labio superior.

Si la estructura geométrica de San Lorenzo 8 es muy semejante a la de San Lorenzo 5, ésta de San Lorenzo 9 se emparienta con San Lorenzo 1. Las cuatro constituyen el grupo de mayor semejanza en aspectos de forma y principios de proporción armónica.

El método olmeca al usar la sección áurea revela, me parece, un aspecto primordial: la simbolización de lo terrenal del cosmos y de la eternidad. Los rostros humanos están investidos con rasgos de apariencia natural; pero su estructura, basada en patrones de armonía absoluta, los colocan en una dismensión ideal. Los escultores olmecas fueron sabios conocedores de la naturaleza del hombre; representaron con exactitud su aspecto físico, pero lo trascendieron ajustándolo idealmente a leyes de máxima perfección.

Con motivo de la presencia de estas tres Cabezas Colosales de San Lorenzo en el nuevo Museo de Xalapa, me pareció oportuno hacer una relación de ciertos aspectos esenciales de esta manifestación plástica sin equivalencia en el arte universal. Las Cabezas Colosales son un hecho inigualable en el arte y en la cultura de la humanidad.

La exhibición de dos Cabezas poco conocidas, la 7 y la 8 , y de una, la 9, publicada hasta ahora, viene a consolidar la verdad del juicio acerca del alto grado de civilización alcanzado por los olmecas. Sólo un pueblo conocedor de los más altos valores, pudo tener la capacidad de expresar ese humanismo fundamental. 